\title{
REPRODUÇÕES EM MADONNARO: PROPONDO UMA ESTRADA PEDAGÓGICA DE MÃO DUPLA ENTRE O MUSEU E A ESCOLA
}

\author{
REPRODCUTION IN MADONNARO: A TWO-WAY LEARNING STREET \\ BETWEEN MUSEUM AND SCHOOL.
}

DOI: http://dx.doi.org/105965198431781212016006

Marcelo Amaral Coelho - RME-RJ

\begin{abstract}
RESUMO:
Este trabalho pretende analisar a reprodução como possibilidade educativa na escola, como referência para a criação artística e, no contexto do museu, como elemento de comunicação do acervo. Assim: Quais as possibilidades de trocas educacionais entre ambas as instituições? $\mathrm{Na}$ busca por respostas refletimos sobre o termo 'Educação' e a relação escola e museu, sem esquecer suas pedagogias. Considerando a reprodução como imagem de um objeto artístico museal, foi inevitável não abordar a Educação Patrimonial. Assim sendo: Qual uso faz a escola no trabalho com a reprodução? Qual o papel da reprodução no contexto museal? Inicialmente se pesquisou sobre o papel da reprodução durante o Renascimento e em seguida sobre seu aspecto comunicativo no contexto do museu. O Madonnaro se desenha como atividade de natureza procedimental para o diálogo entre a escola e o museu. Relatamos ainda os resultados de uma experiência de campo a partir do projeto Madonnaro na escola: mediando saberes, desenvolvido com alunos do Ensino Fundamental, anos finais, no Colégio Wanderley Menezes, em Itaguaí (RJ). A partir disso foi possível perceber o Madonnaro como possibilidade pedagógica tanto para a educação não-formal quanto para a educação formal.
\end{abstract}

Palavras chave: Arte Educação. Educação Patrimonial. Madonnaro. Museu.

\begin{abstract}
:
This paper aims to analyze the reproduction as an educative possibility at school, as a reference to the artistic reproduction and, in to the museum context, as a communication element about the museum's works. What are the knowledge exchanges between both institutions? By looking for answers us reflection the term "Education" e the relation be tween school and museum, without forgetting about its pedagogies. Considering that the reproduction as an image of a museum artistic object was unavoidable not to talk about the Heritage Education. In which ways can the reproduction be used at school? What's the importance of the reproduction in the museum context? Firstly it was researched about the paper of the reproduction during the Renaissance and then about its communicative aspect in the museum context. The "Madonnaro" can be defined as a procedural activity to the dialogue be tween school and museum. Finally it was written about a field experience of the Madonnaro's Project at school: mediating knowledge, developed with the students from the School Wanderley Menezes, in Itaguaí (RJ). It was possible o realize that Madonnaro is a pedagogic possibility even for an education outside school or a schooling.
\end{abstract}

Key Words: Art Education. Heritage Education. Madonnaro. Museum. 


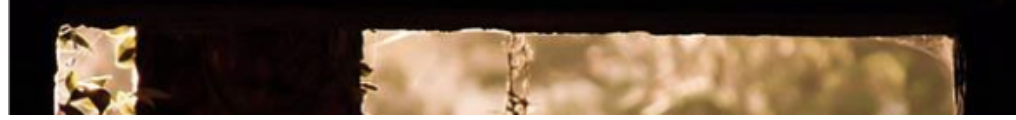

\section{INTRODUÇÃO}

O trato com a imagem reproduzida no âmbito educacional sempre foi muito complexo. Já se viu a reprodução como cópia, releitura e referência. Especificamente no campo das artes, desde o Renascimento italiano, quando se institucionalizou o ensino artístico, a reprodução tem sido motivo de controvérsias. O limite entre o bom e o mau uso das imagens reproduzidas é muito tênue. Porém, não há como negar a possibilidade de obter informações sobre o mundo olhando uma reprodução impressa. No entanto, transformar tais informações em conhecimento é muito mais significativo no contato direto com o objeto reproduzido. As reproduções impressas devem atuar apenas como estimuladores, despertando o que Freire (1996) vai denominar como “curiosidade epistemológica". Sendo assim, tanto a escola quanto o museu - enquanto instituições de ensino - são responsáveis por desenvolver ações que contemplem o bom uso da reprodução impressa.

\section{O MUSEU E A ESCOLA: ESPAÇOS DEM DEFINIDOS}

$\mathrm{O}$ original do termo revela que educação é conduzir alguém para além de si mesmo. Melhor: para além de suas imperfeições - considerando o conceito freireano do ser humano como 'inacabado', em constante (re)construção. Nessa direção, a educação é libertadora. Sendo assim, resultado dos valores, conceitos, práticas e saberes que dinamizam o desenvolvimento do indivíduo; se constituindo num processo contínuo presente em todas as esferas da relação humana. A todo o momento estamos aprendendo ou ensinando. É possível aprender também na feira, no estádio de futebol, e em outros lugares. Aos espaços de ensino-aprendizagem fora da esfera escolar, os estudiosos denominam 'não formal'. Em termos de conceituação, o que são os espaços formais e não-formais de educação? A questão é complexa...

Jacobucci $(2008$, p. 56) lança um olhar sobre a questão e aceita como espaço formal escolar aquele descrito no âmbito da LDB n 9394/96, onde se lê: "É a escola, com todas as suas dependências: salas de aula, laboratórios, quadras de esportes, biblioteca, pátio, cantina, refeitório". Quanto aos espaços não formais de educação, aqueles fora da esfera escolar, Jacobucci os divide em dois grupos: os institucionalizados e os não institucionalizados. Aqueles comportam museus, centros de ciências e outros locais onde haja uma equipe técnica responsável; já a casa, a rua e outros, por sua vez, permitem a educação de maneira informal, sem um mediador e ainda não possuindo uma equipe técnica e institucional. Dessa maneira, num primeiro momento, é possível constatar que, em termos gerais, o espaço físico é que vai determinar os limites entre a educação formal e aquela não-formal ou informal. 
O museu e a escola foram adotados como espaços protagonistas de educação a fim de pensar o argumento deste artigo. Então: que espaços são esses? A prof ${ }^{a}$ Magaly Cabral recorreu a uma definição do ICOM (1989) para conceituar o museu:

(...) é uma instituição permanente, sem fins lucrativos, a serviço da sociedade e de seu desenvolvimento, aberta ao público, e que adquire, conserva, pesquisa, comunica e expõe, com a finalidade de estudo, educação e lazer, os testemunhos materiais do homem e seu meio ambiente. ${ }^{2}$

Por sua vez, Santos (2008, p. 04) tem uma definição de escola muito próxima desta para o museu. Escreveu ela:

(...) a escola é uma instituição que faz parte do patrimônio cultural e, ao mesmo tempo, é alimentada por diversos patrimônios culturais, representados pelo conhecimento produzido e acumulado ao longo dos anos, resultado da herança cultural construída pelos sujeitos sociais ao longo da vida, ou seja, a tradição, que deve ser compreendida, também, como um processo de construção e reconstrução.

Ambos, a escola e o museu, podem ser considerados espaços de desenvolvimento humano motivados por processos de construção e reconstrução, ou seja, locais onde se aprende a aprender. Após a reflexão quanto ao espaço físico como elemento de demarcação para a educação formal e não-formal, considerando a especificidade exigida aos seus mediadores, há que ater às particularidades de suas metodologias e pedagogias.

Então, como aprender na escola e no museu? Há que se considerar que a escola e o museu têm suas próprias pedagogias. As especificidades e os contextos de ambos os espaços exigem ações personalizadas. O museu é um espaço diferenciado da escola. A dinâmica conceitual de um museu em muito se difere da escola. A escola tem o público em seu espaço por mais tempo; ao passo que, no museu, a transitoriedade é permanente. Allard e Boucher (apud DESVALLÉES e MAIRESSE, 2013, p. 39) definiram a prática educativa do museu da seguinte maneira:

A pedagogia museal é um quadro teórico e metodológico que está a serviço da elaboração, da implementação e da avaliação de atividades educativas em um meio museal, atividades estas que têm como objetivo principal a aprendizagem dos saberes (conhecimentos, habilidades e atitudes) pelo visitante.

Tal prática educativa museal deve elaborar ações de mediação com o objeto em exposição de modo a considerar o público fruidor. A mediação deve problematizar para 
acessar ao conhecimento. O conceito de museu integral, estabelecido a partir do encontro realizado em 1972, no Chile, conhecido como "Mesa de Santiago", entende a experiência museal voltada a provocar a curiosidade epistemológica ${ }^{3}$ no indivíduo que adentra aquele espaço.

Quanto à pedagogia escolar, a história revela as várias tendências quanto aos processos de ensino. Processos estes, que se deram a partir das inúmeras interferências na sociedade, “(...) caracterizadas pela dinâmica social que interfere, modificando ou conservando as práticas vigentes" (FERRAZ, 1999, p. 28). Dentre as interferências, se fazem notar: uma prática artístico-educacional voltada para o trabalho - herança do século XIX; a influência das escolas ditas 'tradicional' e 'nova'; os conflitos e pretensões da LDB 5692/71; o papel das associações de arte-educadores - marcando posição a partir do início da década de 1980; a luta pela obrigatoriedade do ensino de artes e renovação da LDB pós-Constituinte de 1988; foco nos cursos de pós-graduação visando preparar professores na área de artes; a influência da arte contemporânea na educação; discussões em torno dos conceitos e metodologias do ensino artístico; e, por fim, a elaboração dos PCN's (1997-8) e o Referencial Curricular Nacional para a Educação Infantil (1998).

O ponto de partida para uma rápida revisão pedagógica da educação é a Pedagogia Tradicional que vê o aluno como uma matriz a receber informações a serem reproduzidas posteriormente. Na década de 1930, sedimentada pela Escola Nova, surge no cenário educativo brasileiro a Pedagogia Renovada, focada nos conteúdos escolares e desconectada com o universo extramuros. No final dos anos 1960 predomina a Pedagogia Tecnicista explorando os recursos tecnológicos da época para uma metodologia de aplicação centrada na aprendizagem pelo esforço e recompensa. Na contramão tecnicista, vem o educador Paulo Freire com sua Pedagogia Libertadora, na qual o diálogo entre educando e educador é a base da aprendizagem. As ideias de Freire abrem caminho para aquela pedagogia denominada Crítico-Social, difundida por Saviani. Nela, os conteúdos são discutidos e reavaliados para a democratização do conhecimento, além da valorização da bagagem cultural do aluno.

Os anos 1980 vão apontar uma mudança de rumo na educação brasileira. Em especial, na arte-educação. Em fins dessa década, mais especificamente no ano de 1987, nasce uma iniciativa que, à época, ficaria conhecida como 'Metodologia Triangular' ${ }^{\text {. }}$ A proposta de Ana 
Mae Barbosa era inspirada na experiência americana da Fundação Getty Center for Education in the Arts (história da arte, estética, crítica e produção), baseada na D.B.A.E, ou seja, Discipline Based Art Education - Ensino da Arte Baseado em Disciplinas. O ensino de arte em voga por aqueles tempos, nos EUA e Inglaterra, previa o ensino de arte baseado no conhecimento histórico, na análise crítica e na produção prática (MUSEU LASAR SEGALL apud FRANZ, 2001). Tal abordagem ofereceu uma alternativa ao ensino artístico baseado no mero espontaneísmo traduzido em releituras 'soltas'. O interessante é que, ao passo que na história a pedagogia escolar ofereceu modelos de ações educativas ao museu, no caso da proposta de Ana Mae Barbosa, o caminho se deu de maneira inversa: a 'Metodologia Triangular' surgiu no espaço do Museu de Arte Contemporânea de São Paulo e ganhou o espaço formal da escola.

Considerando a definição de Allard e Boucher, abordada anteriormente neste texto, e a trajetória pedagógica nacional da educação formal é possível notar que a pedagogia que configura a educação museal em muito se aproxima dos parâmetros estabelecidos para gerir e motivar a educação formal brasileira contemporânea. Quais são: os saberes suscitados a partir de uma aprendizagem pautada nos conteúdos de caráter conceitual, atitudinal e procedimental $^{5}$. O que coaduna com as decisões estabelecidas a partir da Declaração de Santiago (1972) que prevê uma integração da educação museal com a política nacional de ensino ${ }^{6}$.

Tanto a escola quanto o museu podem explorar o conhecimento histórico, a crítica e o fazer como caminhos de aprendizagem. Embora, por questões contextuais, principalmente pelo fato de ter o público por mais tempo em seu espaço, a escola se utilize melhor desta proposta. Pode ser que, nesse sentido, observando tal 'vantagem' da escola sobre o museu, Denise Grinspum tenha sugerido: “(...) o museu deve priorizar a leitura da obra de arte. $\mathrm{O}$ fazer e a história da arte, nem sempre são possíveis.” (FRANZ, 2001, pp. 45).

\section{A DESESCOLARIZAÇÃO DO MUSEU PARA UMA RELAÇÃO DE INTERDEPENDÊNCIA}

Estabelecida uma relação conceitual bem definida de educação entre museu e escola convém pensar como se deu o contato entre essas instituições ao longo dos tempos. Ocorreram muitas mudanças desde a concepção grega de mouseion, ou seja, templo das musas $^{7}$, até o conceito de museu como 


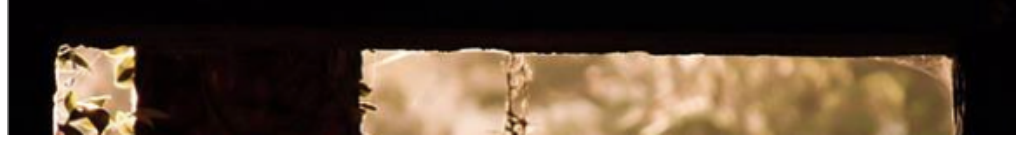

(...) uma instituição permanente, sem fins lucrativos, a serviço da sociedade e do seu desenvolvimento, aberta ao público, que adquire, conserva, estuda, expõe e transmite o patrimônio material e imaterial da humanidade e do seu meio, com fins de estudo, educação e deleite (ICOM apud DESVALLÉES \& MAIRESSE, 2013, p. 64).

Dessa concepção mitológica até a era dos museus espetáculos, onde o próprio prédio é a obra de arte, passando pelo colecionismo dos gabinetes de curiosidades, até a Revolução Francesa de 1789, se deu um hiato entre o acervo e o público em geral. O que inevitavelmente compreendia a escola ou suas mais remotas concepções. Foi a partir dos ideais franceses de liberdade, igualdade e fraternidade ${ }^{8}$ que se pensou o museu como espaço de acesso ao público - ainda que timidamente.

A relação escola museu é antiga. Koptcke (2005, p. 198) localiza as primeiras interseções no ano de 1795, quando aspirantes a professores eram recomendados a visitar bibliotecas, observatórios e museus. Nos arquivos do Museu Histórico Nacional do Rio de Janeiro, em 1832, existem documentos que apontam uma parceria com a escola. Um documento feito circular pela Regência dizia:

Manda submeter o Oficio incluso da Sociedade de Instrução Elementar, em que pede se lhe facultem duas salas, que existem no pavimento baixo do edifício do Museu Nacional, a fim de estabelecer uma Escola (...) para fazer o ensaio de um sistema que tem adaptado com vistas de melhorar entre nós a Instrução Primária (...) (KOPTCKE, 2005, p. 198).

Acompanhando o modelo em vigor na Europa e EUA, desde o decorrer do século XIX, o Brasil explorou a escola e o museu como espaços para a "formação do cidadão republicano". Naquele contexto, à medida que a escola adotava as práticas demonstrativas como recurso de ensino mais se aproximava do museu. $\mathrm{O}$ art. 59 de um documento publicado em 1911 (Decreto de 15/12/1911, AMN) propõe "a criação de um museu escolar de história natural em um das dependências do museu, destinado ao ensino intuitivo, especialmente para crianças" (idem). Tal iniciativa seguia o modelo francês em vigor desde 1893. Modelo este baseado numa relação de complementaridade. A educação museal naquele período se baseava no

(...) conceito museu-escola, disseminado pelo movimento a favor da vulgarização do ensino de história natural no hemisfério norte, determinando mudanças na função educativa do Museu (LOPES apud KOPTCKE, 2005, p. 200). 
No decorrer dos anos, a educação museal passou por transformações. O museu se desescolarizou. Aquela relação passiva de complementaridade mudou para um relacionamento de interdependência com a escola onde

o museu passa a partir disso para o papel de escola informal, não dependendo de uma escola formal para ser válido, pois o aprendizado que se pode garantir através das imagens e objetos presentes no museu é mais intenso se misturado com as idéias e pensamentos obtidos dentro de sala de aula (GIRARDI, 2010, p. 14).

A partir dessa descolarização, que resultou numa interdependência, o museu assumiu de fato sua função educacional. Agindo assim, como dissemos acima, o museu problematizaria o acervo para a produção de conhecimento. Lopes (1991, p. 443) cita VarineBohan para explanar as três funções educacionais do museu. Aquela primeira, de ordem terapêutica, vê o público como “objetos da animação". Outra, de natureza promocional, segundo Lopes, "dominante nos museus", parece voltada à cultura da matéria, ou seja, requer tão somente a promoção do museu e a valorização de seu acervo. Sob essa ótica - míope, por sinal - "sua finalidade é difundir um produto". Aqui, a visão de educação museal se desenvolve numa verticalidade que não considera os interesses do público. Continua Lopes (ibidem, p. 444): “A terceira categoria de animação, a conscientizante, é uma proposta de ação comunitária para a transformação cultural e social, pelo incentivo à participação ativa e à criatividade dos usuários". Seguidor das ideias de Paulo Freire, Varine considera as duas primeiras correntes como 'educação bancária' e paternalista. Porém, aquela conscientizante corresponde a uma educação libertadora.

\section{A EDUCAÇÃO PATRIMONIAL: UMA NOVA VISÃO DO OBJETO}

Foi intencionando uma nova visão educacional libertadora na área museal que, considerando a possibilidade de uma educação a partir do objeto, se empreendeu, no início da década de 1980, aquela que ficou conhecida como "Educação Patrimonial"". Tratava-se de uma metodologia implantada por Maria de Lourdes Parreiras Horta, em 1983, após retornar de um curso voltado a professores no trabalho com monumentos, realizado na Inglaterra. Horta definiu essa nova metodologia como “(...) o ensino centrado no objeto cultural, na evidência material da cultura. Ou ainda como o processo educacional que considera o objeto como fonte primária de ensino.” (HORTA apud CABRAL SANTOS, 1997, p. 32) 
Com o passar do tempo a definição primeira de Horta foi se alterando. Na década de 1990, a ideia de "material da cultura" é mudada para "cultura material" focada numa "visão mais humanística" do patrimônio. Segundo Horta (idem) a Educação Patrimonial se vale das relações e interações entre aquilo que conhecemos e o que estamos a conhecer para se estabeleça um novo saber. Nessa perspectiva, "o questionamento, a experimentação, a representação são recursos educacionais que podem nos levar a esse conhecimento". No entanto, a má interpretação da metodologia da Educação Patrimonial rendeu muitas críticas. Ao que Horta considera interessante já que suscita o debate. Porém, muito se disse e pouco se concluiu sobre o que seja - ou foi - a Educação Patrimonial.

Cabral Santos (1997, p. 38) elaborou um quadro comparativo (Fig. 01) sobre as mudanças quanto ao conceito metodológico da Educação Patrimonial. Eis que segue:

\begin{tabular}{|l|l|l|l|l|l|}
\hline \multicolumn{2}{|c|}{1983} & \multicolumn{2}{c|}{1993} & \multicolumn{2}{c|}{1994} \\
\hline ETAPAS & OBJETIVOS & ETAPAS & OBJETIVOS & ETAPAS & OBJETIVOS \\
\hline Registro & $\begin{array}{l}\text { Identificação } \\
\text { do significado } \\
\text { do signifiçado } \\
\text { Análise e jul- } \\
\text { gamento críti- } \\
\text { co; Extrapola- } \\
\text { ção do signifi- } \\
\text { cado }\end{array}$ & $\begin{array}{l}\text { Observação } \\
\text { cesso cultural } \\
\text { que está no } \\
\text { objeto }\end{array}$ & $\begin{array}{l}\text { Identificação } \\
\text { do Bem } \\
\text { Cultural }\end{array}$ & $\begin{array}{l}\text { Observação e } \\
\text { Análise }\end{array}$ \\
\hline Participação & $\begin{array}{l}\text { Compreensão } \\
\text { processos os } \\
\text { empatética } \\
\text { (envolvimen- } \\
\text { to afetivo) }\end{array}$ & $\begin{array}{l}\text { Registro do } \\
\text { Bem } \\
\text { Cultural }\end{array}$ & $\begin{array}{l}\text { Registro da } \\
\text { Identificação }\end{array}$ \\
ção & $\begin{array}{l}\text { Irapola- } \\
\text { tes do objeto e } \\
\text { além deles }\end{array}$ & $\begin{array}{l}\text { Valorização } \\
\text { e Resgate }\end{array}$ & $\begin{array}{l}\text { Interpretação e } \\
\text { comuniçãa } \\
\text { do significado }\end{array}$ \\
\hline
\end{tabular}

Fig. 1 - Quadro que reflete as mudanças no conceito de Educação Patrimonial

A partir do quadro elaborado acima, nota-se que entre 1983 e 1993, a "Extrapolação", que antes estava subordinada ao "Registro", ganhou categoria própria para impulsionar a experiência museal para além do objeto. Em 1994, Evelina Grumberg - parceira de Horta na aplicação desta metodologia - definiu a metodologia da Educação Patrimonial como: observação e análise gerando a identificação - registro da identificação possibilitando a interpretação - valorização e resgate para a compreensão emocional e estética.

Em termos gerais, existe a possibilidade de reflexão a partir do objeto. No caso da presente pesquisa, o objeto é a reprodução impressa da obra artística como meio de familiarização ${ }^{10}$ com o acervo do museu. Eis que surge a pergunta: como é utilizada pedagogicamente a reprodução impressa na escola? É fato que em muitas salas de aula a 
reprodução impressa tem sido explorada como cópia e não como referência. No caso de uma aula de desenho ou pintura, o trabalho é considerado bom quando apresenta um alto grau de fidelidade ao original. Sem contar a herança das releituras tão em voga num determinado período da prática de ensino artístico no Brasil.

\section{A REPRODUÇÃO IMPRESSA COMO REFERÊNCIA}

A fim de refletir sobre a construção de uma imagem a partir da reprodução impressa, se tomou como referencial o contexto do Renascimento. Por aquela época, o desenho era considerado o "padre delle arti", já que "ad esso è affidato il compito di visualizzare l'idea insita nella mente dell'artista" "11 (RODINÒ, 1991, p. 103). Teoria esta que vai permanecer até o século XVIII, se constituindo na base do ensino tradicional de arte $^{12}$. Portanto, pode ser o desenho uma maneira de instituir um ponto de partida pedagógico para refletir entre cópia e estudo de referências. Nas botteghe renascentistas, os jovens aprendiam copiando dos cadernos dos mestres - produzindo não uma cópia fiel, mas um exercício estilístico e formal. Os cadernos “(...) costituivano il bagaglio iconografico e stilistico di scuole, periodi e movimenti artistici" ${ }^{\prime 13}$ (ibidem, p. 127).

O ensino artístico a partir da cópia era uma herança medieval. A mudança didática vai acontecer em Florença, por volta do século XV. Em meio ao pensamento científico da época, Pisanello empreende os primeiros traços para a 'captura' da imagem direto do real. É quando o desenho se apresenta como forma de pensamento, pesquisa e reflexão. Aqueles cadernos de desenho não continham desenhos finalizados, mas inúmeros exercícios de linha, claro-escuro e particulares formais (ibidem, p. 131). Assim sendo, os desenhos eram feitos a partir da observação da realidade, “(...) il grande libro della natura” (ibidem, p. 141) ${ }^{14}$. Mediante essa observação e o contexto de indagação surgido com o Renascimento, é possível supor que a nova postura diante do objeto era tê-lo como referência e não como mera cópia.

A reprodução impressa, dentro do contexto museológico, pode ser classificada como 'comunicação', já que aparece como possibilidade de acesso ao objeto através da imagem. A comunicação é uma das funções do museu. Um dos tópicos-desafios elaborados a partir da Carta de Petrópolis (2010) era: "Estimular a promoção e a difusão do conhecimento produzido na área educacional do museu" (PNEM, 2013, p. 66). Essa estimulação, enquanto comunicação, ganha forma a partir das exposições. Quando realiza uma exposição, o museu comunica um potencial conhecimento. Os objetos em exposição podem deixar o espaço físico 
do museu e rodar o mundo por meio das reproduções. Algumas das resoluções estabelecidas a partir da Declaração de Santiago (1972) apontam nessa direção. Diz o documento quanto ao papel educacional do museu: "deverão ser difundidos nas escolas e no meio rural, através dos meios audiovisuais, os conhecimentos mais importantes" e "deverá ser utilizado na educação, graças a um sistema de descentralização, o material que o museu possuir em muitos exemplares" (LEGISLAÇÃO SOBRE MUSEUS, 2013, p. 105). A imagem reproduzida pode se constituir num elemento mediador. Portanto, a comunicação oriunda do contato com reprodução impressa deve ser interativa e instigadora. Dessa interação pode vir a nascer a possibilidade educativa para a criação.

\section{O MADONNARO COMO INSTRUMENTO PEDAGÓGICO}

Dentre muitas técnicas de pintura que se utilizam da reprodução impressa como referência está o Madonnaro. A técnica, que consiste em pintar sobre o chão com gizes, vai aparecer no cenário artístico, no século XVI, em Veneza, na Itália. Por conta das reproduções da Madonna ${ }^{15}$ é que tais artistas seriam denominados "madonnari"". Devido à sua materialidade, o Madonnaro logo se desfaz seja pela chuva, pelos passos apressados das pessoas ou pelas ações de limpeza urbana. Trata-se de uma arte de processo e não um produto final. E mais: não danifica o patrimônio físico e cultural. ${ }^{17}$

Dentre as vantagens pedagógicas do Madonnaro estão o baixo custo com os materiais. É possível fazer pintura no chão tendo em mãos cacos de tijolo, carvão para churrasco e giz branco. Mais: é ainda viável o ensino dos fundamentos da pintura para a construção da imagem. Quais são: desenho, cor, claro-escuro, etc. Há que se atentar também ao aspecto lúdico do ato de desenhar com giz pelo chão. Em novembro de 2015, quando convidados a participar do evento "Cultura na Praça”, organizado pela Prefeitura Municipal de Mangaratiba (RJ), na Praça do Skate, em Muriqui, tivemos a oportunidade de produzir um Madonnaro. Qual foi nossa surpresa: não demorou para que várias crianças se dirigissem a nós a fim de obter um giz e também lançar seus riscos e rabiscos sobre o chão.

Assim, entendendo tais vantagens, é que o projeto "Madonnaro na escola: mediando saberes" 18 foi pensado como instrumento para se trabalhar os conteúdos de pintura, história da arte e fazer artístico. Como referencial teórico-imagético recorreu-se ao Salão Preto e Branco (1954), um importante capítulo da história cultural brasileira. Esse evento forneceu o direcionamento para as escolhas das reproduções impressas a serem trabalhadas como referenciais. O projeto aconteceu com os alunos do ensino fundamental II, do Colégio Wanderley Menezes, em Itaguaí (RJ). Pretendia-se como objetivo principal a apresentação da técnica do 
Madonnaro como possibilidade de fazer artístico e as reproduções impressas como referência histórica, critica e criativa. Para isso, foi necessário aos alunos: conhecer a técnica do Madonnaro; contextualizar a cultura de outras sociedades; perceber o preto e o branco como recursos para a criação artística; entender a importância do Salão Preto e Branco; ver o espaço físico da escola como patrimônio a ser preservado; e produzir um Madonnaro.

Cada uma das turmas do Ensino Fundamental II trabalhou com um artista específico relacionado ao Salão Preto e Branco de 1954: Milton Dacosta (6 ${ }^{\circ}$ ano); Renina Katz ( $7^{\circ}$ ano); Iberê Camargo ( $8^{\circ}$ ano); e Oswaldo Goeldi ( $9^{\circ}$ ano). A escolha dos artistas considerou, além do envolvimento no dito salão, aspectos técnicos como as formas 'recortadas', a linha 'econômica', a composição simples e a 'proximidade' temática com o cotidiano dos alunos. O fato de estarem iniciando o contato com o Madonnaro requereu que experimentassem formas menos complexas, sem 'passagens' tonais ou desenhos 'renascentistas'.

Num primeiro momento foi trabalhada com os alunos a história do Madonnaro. Eles puderam conhecer a origem da prática, a passagem de gênero à técnica pictórica e os procedimentos técnicos e materiais necessários. Um texto distribuído à turma informava que:

\footnotetext{
Por toda a Itália observam-se artistas desenhando pelo chão. Durante o ano são realizados eventos pelo país reunindo esses 'artistas de estrada'. Essa técnica é conhecida como MADONNARO - 'Madonnari' quando referente ao plural. Também os artistas que se utilizam da prática são denominados 'madonnari'. A técnica é conhecida assim porque a maioria dos desenhos representa a imagem da Madonna Virgem Maria. Ao longo do tempo, o Madonnaro expandiu-se por outros caminhos. Hoje existe o Madonnaro sobre tela e também o Madonnaro anamórfico (perspectiva, ilusão de ótica). Pelo mundo, e não somente na Itália, se pratica o Madonnaro.
}

Segundo a tradição e o contexto mercantilista de Veneza no século XVI, que via no ícone religioso uma fonte de renda, “o 'desenho' da Madonna deveria ser uma cópia do original”, ou seja, “(...) o primeiro retrato de Jesus de Nazaré e de sua Mãe” (NAALIN apud COELHO, 2016). O Madonnaro, enquanto técnica de pintura no chão, surgiu como uma alternativa ao 'mercado de arte' em vigor à época. Os artistas madonnari iam pelos santuários a “(...) reproduzir as obras de Rafael ou de Michelangelo ou mais simplesmente o aumento de qualquer imagem reproduzida em 'santinhos"' (idem). Viviam das 'ofertas' dadas por aqueles que passavam para lá e para cá.

Foi ressaltado ainda que o Madonnaro tem como uma de suas características essenciais a efemeridade. Por tradição é feito sempre ao ar livre. Isso o torna uma arte de curtíssima durabilidade, existindo apenas no momento de sua criação. Logo é “(...) anulado 


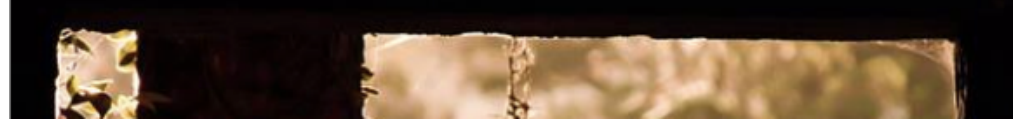

pela primeira chuva ou pelos passos dos apressados pedestres" (idem). Entretanto, essa mesma efemeridade fez com que o Madonnaro se constituísse em uma arte que dialoga perfeitamente com o espaço físico - das igrejas à época até as escolas, casas, prédios, calçadas, e outros espaços na atualidade.

Ainda nesse momento, ressaltando a metodologia tradicional de criação de um Madonnaro, sugerimos como procedimento artístico aos alunos as seguintes etapas: 1) Estudo da referência (tema, linear, cromático, etc); 2) Escolha do pavimento evitando buracos, irregularidades, marcas de óleo, chicletes, etc; 3) Demarcação a área; 4) Quadrícula; 5) Esboço do desenho; 6) Definição do desenho; 7) Aplicação das cores. Passamos ainda aos alunos que os primeiros Madonnari eram feitos com materiais simples e sustentáveis. São eles: cacos de tijolos, carvão, gesso e terra colorida.

Em uma segunda aula, as turmas foram ao pátio da escola a produzirem um Madonnaro livre, a fim de experimentarem a materialidade da técnica. Além da atividade prática, os alunos deveriam produzir um breve relatório. O conteúdo deste relatório deveria versar sobre a experiência com a materialidade do Madonnaro. Como introdução, nós estivemos a produzir um Madonnaro para que os alunos pudessem observar o trato com o material e o procedimento de construção. Depois, cada aluno recebeu carvão e giz branco e puderam se espalhar pelo pátio a criarem seus desenhos.

$\mathrm{Na}$ aula seguinte foi apresentado o Salão Preto e Branco e sua importância artística, histórica e social. Também nesta aula dispusemos aos alunos cópias com um texto referente ao conteúdo conceitual do assunto. O III Salão Nacional de Arte Moderna, organizado em 1954, foi uma reação da classe artística a uma imposição do governo. Constava no manifesto divulgado por aqueles artistas:

\footnotetext{
Esta atitude será um veemente protesto contra a determinação do governo em manter proibitiva a importação de tintas estrangeiras, materiais de gravura e escultura, papéis (sic) e demais acessórios essenciais ao trabalho artístico; proibição esta que consideramos um grave atentado contra a vida profissional do artista contra os altos interesses do patrimônio artístico nacional (abril de 1954) (FERREIRA apud LUZ, 2010, p. 92).
}

Para isso, instituíram no mesmo documento: "Nós, os artistas plásticos abaixoassinados, apresentaremos no próximo Salão Nacional de Arte Moderna, a se realizar de 15 de maio a 30 de junho deste ano, os nossos executados exclusivamente em branco e preto" 
(idem). Foi com base numa analogia com o 'título-protesto' do Salão que exploramos a materialidade do carvão e do giz como instrumentos para a prática Madonnaro no pátio da escola.

A quarta aula apresentou aos alunos os processos de criação de uma produção artística. Os alunos tiveram acesso a um conjunto de três reproduções impressas dos artistas escolhidos para serem trabalhados em sua turma. Para cada imagem, de acordo com os pressupostos da Proposta Triangular, de Ana Mae Barbosa, foi feita uma leitura visual preliminar. Em seguida, com base em Arnheim ${ }^{19}$, foram trabalhadas noções de equilíbrio, configuração, forma, espaço e cor. Noções estas, caras ao processo criativo. A partir do contato com as reproduções impressas desses artistas, observando-as com cuidado, cada aluno pode criar uma nova imagem a partir de seus elementos formais internos e estilo. Foi quando, dividindo o espaço da folha A4 em quatro partes iguais, eles puderam criar diferentes possibilidades para o desenho final.

Em outra aula, os alunos tomaram conhecimento do método de transporte de imagens (ampliação e redução) conhecido como quadrícula. Neste encontro foi possível conceituar a quadrícula, também conhecida como malha quadriculada, como um recurso que permite uma proximidade com operações matemáticas já que trabalha com linhas horizontais e verticais para o cálculo de uma determinada área. A quadrícula pode facilitar a reprodução de desenhos e desenvolver a capacidade de organização espacial, percepção e concentração. Por meio da quadrícula é possível reduzir ou ampliar qualquer desenho. Potencialidades estas que podem contribuir, em especial, à produção do Madonnaro quando se inicia na técnica. $\mathrm{O}$ recurso do quadriculado é uma prática muito antiga. Comentando o processo de pintura mural do antigo Egito, Mora \& Philippot (2001) sinalizam que aqueles homens já recorriam à quadrícula como recurso para a representação das figuras e dos hieróglifos. Porém, nem todos os artistas fazem uso da quadrícula. Para alguns estudiosos, a quadrícula é útil para reportar imagens pequenas em grandes dimensões. Mas também, existem artistas madonnari que não a usam porque trabalham interpretando o modelo inicial e, portanto, não necessitam de uma restituição 'fiel' da imagem ${ }^{20}$. Ainda nesta aula os alunos realizaram uma experiência de ampliação por meio da quadrícula, a partir de uma reprodução impressa (Fig. 02). 

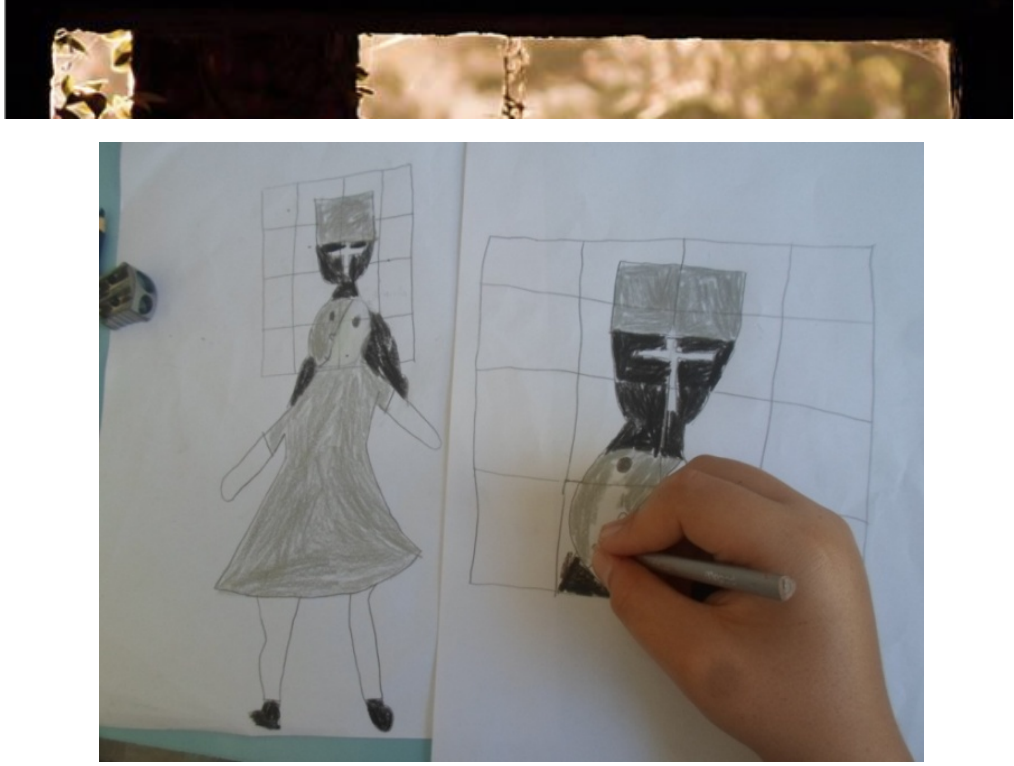

Fig. 02 - Aluno em atividade de ampliação por meio da quadrícula (Acervo pessoal).

De posse das criações feitas em sala de aula e de materiais como o carvão e o giz branco, se deu a produção final do Madonnaro (Fig. 03 ). Os resultados foram recriações a partir das reproduções impressas oferecidas como referenciais em sala de aula e progresso técnico, levando em consideração a primeira aula quando fizeram o uso do material de maneira livre. A atividade foi computada como uma das avaliações para aquele bimestre. Uma segunda avaliação foi a prova escrita. Nela, abordamos os assuntos trabalhados em sala como conteúdos conceituais. Dentre as questões que compuseram a avaliação bimestral, perguntamos: O que significou para você produzir uma obra em Madonnaro? Eis algumas das respostas transcritas literalmente:

- "Uma coisa nova e interessante, me deu vontade de fazer mais desenhos. Me deu um sentimento de liberdade" ( $6^{\circ}$ ano).

- "Pra mim o madonnaro foi uma inspiração pra mim e grasas o madonnaro e estou desenhando melhor. E a quadricula também me ajudou muito" (6 $\left.6^{\circ} \mathrm{Ano}\right)$.

- "Muito interessante e divertido fica fazendo desenhos no chão. Desenhar oque você quiser, mais o triste é saber que um dia vai desaparecer" ( $\left.7^{\circ} \mathrm{Ano}\right)$.

- "Desenhar com giz branco e carvão foi diferente. O ruim é que a qualquer momento será levado pela chuva ou com certeza será gasto de tantas pisadas" ( $7^{\mathrm{o}}$ Ano).

- "Bem legal desenhar no chão uma: por exemplo uma obra que foi feito por vários pintores famosos e fazendo com os amigos fica mais legal competindo qual ficou melhor até que eu melhorei um pouco em desenhar" ( $\left.7^{\circ} \mathrm{Ano}\right)$. 


\section{EDUCAÇÃO, ARTES E INCLUSÃO}

- "Significou pode mostrar que nada é eterno o desenho como a vida são momentâneas efêmeras, mostrou que se tem que aproveitar bastante a vida mais com prudência" ( $7^{\circ}$ Ano).

- "Foi uma aula muito interessante, porque nunca tinha ouvido falar nessa obra e isso significou muito, foi uma aula muito agradável" ( $\left.8^{\circ} \mathrm{Ano}\right)$.

- "Foi bem legal, pelo fato de ser diferente e a aula também foi bem criativa sendo lá fora, achei uma técnica legal mais que podia durar mais" ( $\left.8^{\circ} \mathrm{Ano}\right)$.

- "Significou bastante coisa a arte madonnaro nos mostra que tudo é passageiro, na hora sua obra te passa o que você quer sentir, logo após você vê que sumiu, que nada é eterno... Esse estilo artístico é até uma boa lição de vida" ( $8^{\circ}$ Ano).

- "Significou muito pra mim porque foi legal reproduzir um desenho que eu criei lá fora para todos vêem e essa técnica é legal por isso" ( $\left.9^{\circ} \mathrm{Ano}\right)$.

- "Foi muito legal porque aprendemos uma outra cultura e foi uma grande experiência" ( $9^{\circ}$ Ano).

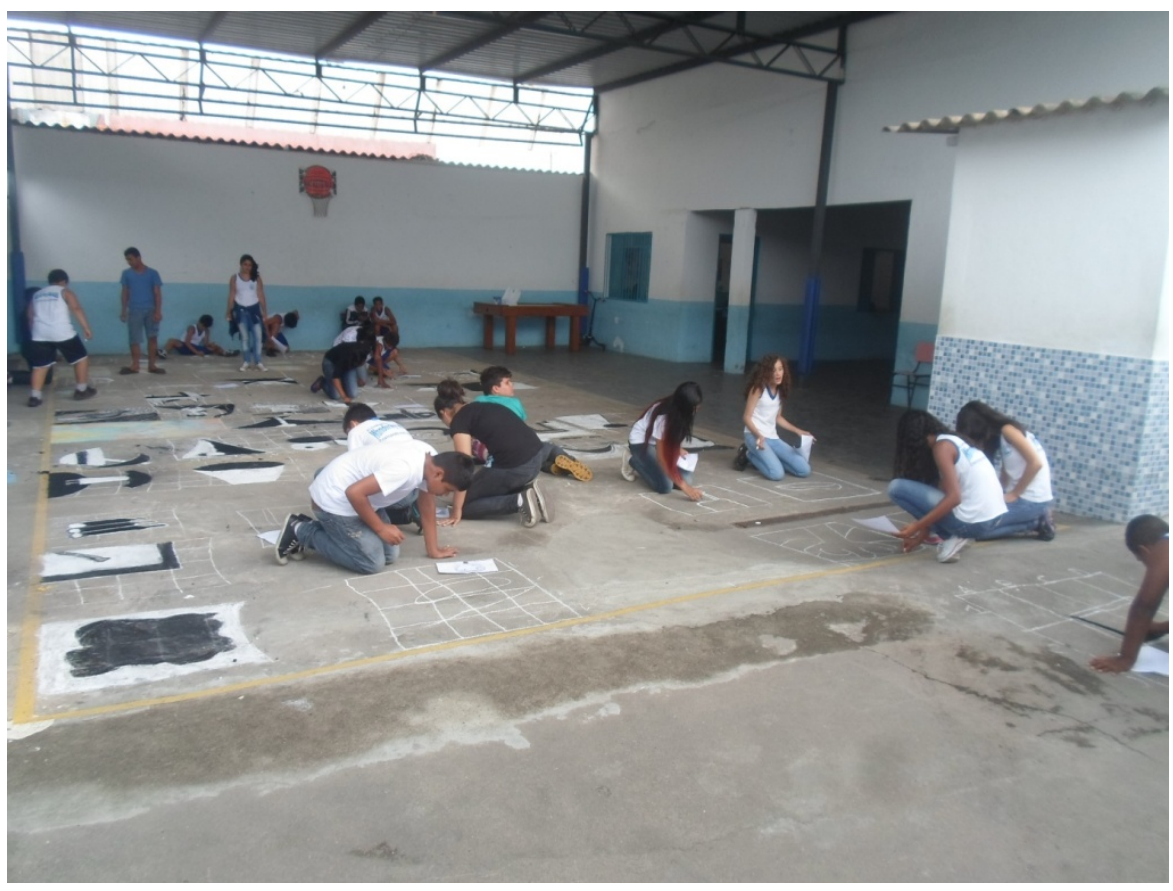

Fig. 03 - Alunos no pátio da escola para a produção final do Madonnaro (Acervo pessoal).

\section{CONSIDERAÇÕES FINAIS:}

O relato da experiência vivenciada com os alunos do Colégio Wanderley Menezes, em Itaguaí (RJ), foi direcionado a mostrar as possibilidades de ensino a partir do contato com a 
reprodução impressa. Os alunos tiveram contato com a história da arte, os processos críticos para a leitura de uma imagem e ainda o fazer artístico. A partir das respostas transcritas acima

foi possível perceber o aprendizado de conhecimentos técnicos, históricos e críticos. Notamse experiências de interculturalidade, autoestima... E até filosofia! Os resultados apontaram ainda que o contato com a obra de arte, ainda que por meio da reprodução impressa, pode facilitar a formação de público para o museu. A partir de agora os alunos sabem da existência daquelas obras de arte. Tendo a oportunidade de entrarem em um museu e se deparando com uma das obras trabalhadas em sala de aula através da reprodução impressa a experiência será muito mais profunda e enriquecedora.

A escola e o museu devem existir numa relação de interdependência. O museu como espaço de problematização de conhecimentos a serem (re)trabalhados na escola - entendido que nesse processo cíclico, se dera um momento de familiarização na escola. A nossa experiência com a familiarização através da reprodução impressa nos permitiu concluir que trabalhamos na direção de uma prática "conscientizante", como priorizou Varrine, para a formação de um público voltado à participação ativa e criativa. Contribuindo, dessa maneira, no discurso freiriano, para a formação autônoma dos alunos com relação à sua própria cultura.

Concluímos ainda que, a utilização da reprodução impressa em sala de aula como referência e não como modelo para cópia, além de promover a familiarização com o objeto cultural, permitiu trilhar caminhos para o desenvolvimento técnico com relação à arte - no caso da presente experiência, a pintura Madonnaro. É quando, segundo o que pudemos observar, a reprodução impressa se fez um elemento mediador de conhecimentos históricoculturais, estéticos e técnicos. Isso sem esquecer que a escola não é um local de formação artística, mas sim um espaço de construção de um público apreciador de arte.

Estava previsto uma visita ao Museu Nacional de Belas Artes, no centro do Rio de Janeiro. Tínhamos pensado assim, por conta da realização do Salão Preto e Branco ter acontecido no Rio de Janeiro e o referido museu conservar em seu acervo a obra Casas da Praia Grande ou Casario (1954), com a qual Francisco Rebolo ganhara o Prêmio de Viagem ao Exterior, neste mesmo salão. Porém, a direção da escola não se mostrou muito interessada em promover a visita e os pais, por sua vez, também não aderiram à ideia. Com isso, não pudemos proporcionar esta vivência aos alunos. 
Por fim, entendemos que a metodologia utilizada fora válida já que a aprendizagem por meio da reprodução é um recurso reconhecido pelos PCN's da educação nacional, seja ela de natureza virtual ou impressa. Se o trabalho de familiarização com o objeto artístico pode ser entendido como uma das tarefas da escola, pode ser por meio da reprodução que o museu fará o caminho inverso e irá até a escola. No processo de educação integral cabe à escola dessacralizar o conhecimento presente nos acervos museais enquanto o museu democratiza o acesso comunicando este acervo. Trata-se aqui, então, de uma possível via de mão dupla.

\section{NOTAS:}

1 "Minha franquia ante os outros e o mundo mesmo é a maneira radical como me experimento enquanto ser cultural, histórico, inacabado e consciente do inacabamento. Aqui chegamos ao ponto de que talvez devêssemos ter partido. $\mathrm{O}$ do inacabamento do ser humano. $\mathrm{Na}$ verdade o inacabamento do ser ou sua inconclusão é próprio da experiência vital. Onde há vida, há inacabamento. Mas só entre mulheres e homens o inacabamento se tornou consciente" (FREIRE, 1996, p. 55).

${ }^{2}$ Escreveu a prof ${ }^{a}$ Magaly Cabral logo no início de sua dissertação de Doutorado (Cap. 1, PUC-RJ, 1997, p. 07). Por sua vez, em 2007, o ICOM, obedecendo as transformações no campo da pesquisa museal, vai ampliar o conceito de museu como: “(...) uma instituição permanente, sem fins lucrativos, a serviço da sociedade e do seu desenvolvimento, aberta ao público, que adquire, conserva, estuda, expõe e transmite o patrimônio material e imaterial da humanidade e do seu meio, com fins de estudo, educação e deleite" (DESVALLÉES e MAIRESSE, 2013, p. 64).

3 "Curiosidade epistemológica" - Tomo aqui uma das expressões de Paulo Freire para aludir ao estímulo direcionado para o conhecimento autônomo por parte do indivíduo. Freire, à época exilado no Chile, foi impedido de participar do evento que mudaria a concepção de educação em museus. No entanto, suas ideias se propagaram a partir da figura de Hughes de Varine, por aqueles tempos presidente do ICOM - Conselho Internacional de Museus - e organizador do encontro na capital chilena. Varrine era confesso admirador da 'pedagogia freiriana'. O relatório final da Mesa de Santiago vem estruturado sobre o pensamento educativo de freire. Para saber mais consultar: ALVES, Vânia Maria Siqueira e REIS, Maria Amélia Gomes de Souza. Tecendo relações entre as reflexões de Paulo Freire e a Mesa-Redonda de Santiago do Chile, 1972. Disponível em: <http://revistamuseologiaepatrimonio.mast.br/index.php/ppgpmus/article/viewFile/253/220 >. Acesso em: 23 de abril de 2016.

${ }^{4}$ Optamos por adotar o termo Metodologia Triangular entre aspas simples como referência ao estado original da ideia e ainda por entender que a própria autora reconhece que não se trata de uma metodologia. Segundo ela, o ideal é reconhecer tal iniciativa como 'Proposta Triangular'. Veja o que escreveu a arte-educadora, em 1998: "Culpo-me por ter aceitado o apelido e usado a expressão Metodologia Triangular em meu livro A imagem no Ensino da Arte. Hoje, depois de anos de experimentação, estou convencida de que metodologia é construção de cada professor em sua sala de aula e gostaria de ver a expressão Proposta Triangular substituir a prepotente designação Metodologia Triangular (BARBOSA apud SCHULTZ, 1991, p. 1210).

${ }^{5}$ Considerando a relação dinâmica do aprendizado e não sua linearidade - que pressupõe "acúmulo" -, o PCN (1998, p. 75 - grifo nosso) diz: "É importante deixar claro que, na escolha dos conteúdos a serem trabalhados, é preciso considerá-los numa perspectiva mais ampla, que leve em conta o papel, não somente dos conteúdos de natureza conceitual - que têm sido tradicionalmente predominantes - , mas também dos de natureza procedimental e atitudinal".

${ }^{6}$ A transcrição do documento redigido em Santiago (Chile), no ano de 1972, traz escrito o seguinte: "deverão ser integrados à política nacional de ensino, os serviços que os museus deverão garantir regularmente" (LEGISLAÇÃO SOBRE MUSEUS, 2013, p. 105).

7 "Segundo a mitologia grega havia nove musas que presidiam as chamadas artes liberais: história, música, comédia, tragédia, dança, elegia, poesia lírica, astronomia e a poesia épica e a eloqüência" (GASPAR, 1993, p. 12). Então, o museu era onde habitavam estas musas.

8 GOMES, Cristiana. Revolução

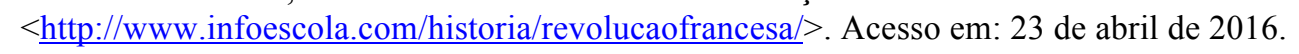




\footnotetext{
${ }^{9}$ Tradução do inglês "Heritage Education".

${ }^{10}$ Familiarização - Conceito defendido por FRANZ, Teresinha Sueli. Educação para a compreensão da arte. Florianópolis: Insular, 2001.
}

11 “(...) 'pai das artes’ (...) “a ele é confiado a tarefa de visualizar a idéia contida na mente do artista” (Tradução nossa).

${ }^{12}$ A institucionalização do ensino artístico no Brasil foi esboçada sobre a concepção neoclássica de desenho, através da implementação da Academia de Belas Artes, pela Missão Artística Francesa, contratada por D. João VI para 'revitalizar' o Rio de Janeiro.

13 “(...) constituíam a bagagem iconográfica e estilística de escolas, períodos e movimentos artísticos” (Tradução nossa).

14 “(...) o grande livro da natureza” (Tradução nossa).

${ }^{15}$ Termo italiano para definir a representação iconográfica da Virgem e o Menino Jesus.

${ }^{16}$ Forma plural italiana para o substantivo "Madonnaro".

${ }^{17}$ NALIN, Felice. L'arte dei madonnari. Le tecniche. Del segno e del colore. Giunti Demetra, 2000.

${ }^{18}$ Para saber mais sobre o projeto e seus desdobramentos sugerimos a leitura do artigo "Madonnaro: mediando saberes na escola a partir do Salão Preto e Branco", apresentado por nós como comunicação oral no VIII Congresso de Pesquisa e Extensão \& III Semana de Ciências Sociais UEMG - campus Barbacena, em 2015. Os organizadores do evento ainda não lançaram os anais com a publicação. Mas o texto se encontra disponível em: COELHO, Marcelo A. Madonnaro: mediando saberes na escola a partir do Salão Preto e Branco $<$ http://artesobrepavimento.blogspot.com.br/2016/03/madonnaro-mediando-saberes-na-escola.html>. Acesso em: 31 de março de 2016.

${ }^{19}$ Para o teórico da Forma Rudolf Arnheim, a criação é transformar coisas em imagens guardando "um mínimo de aspectos estruturais" (configuração) e muita imaginação (formas). Essa imaginação é “(...) a descoberta de uma nova forma para um conteúdo velho (...). A imaginação visual é um dom universal da mente humana, (...). Ocasionalmente são ajudadas observando outras, mas essencialmente agem por conta própria." (ARNHEIM, 1980, p. 132) É quando a criação se faz invenção e a cópia não passa de mera repetição.

${ }^{20}$ Perguntado sobre o uso da quadrícula por artistas madonnari, o professor e artista madonnaro italiano Felice Naalin nos respondeu, via email: "La quadrettatura è utile solo per riportare immagini piccole in grandi dimensioni. Di solito i madonnari non la usano perché l'artista lavora interpretando il modello iniziale e quindi non ha bisogno di una restituzione dell'immagine analitica". Ou seja: A quadrícula é útil só para transportar as imagens pequenas em tamanho maiores. Nem sempre os madonnari a usam porque o artista trabalha interpretando o modelo inicial e, portanto, não tem a necessidade de uma restituição fiel da imagem" (Tradução nossa).

\section{REFERÊNCIAS:}

ALVES, Vânia Maria Siqueira e REIS, Maria Amélia Gomes de Souza. Tecendo relações entre as reflexões de Paulo Freire e a Mesa-Redonda de Santiago do Chile, 1972. Disponível em: $<$ http://revistamuseologiaepatrimonio.mast.br/index.php/ppgpmus/article/viewFile/253/220>. Acesso em: 23 de abril de 2016.

ARNHEIM, Rudolf. Arte e percepção visual: uma psicologia da visão criadora. Trad. Ivone Terezinha de Faria; supervisão editorial de Vicente di Grado, com a participação de Emiko Sooma. S. Paulo: Pioneira; Ed. da Universidade de São Paulo, 1980.

BARBOSA, Ana Mae. Arte-Educação no Brasil. S. Paulo (SP): Perspectiva, 1995.

BRASIL. Documento Preliminar do Programa Nacional de Educação Museal (PNEM). Brasília: MinC/ IBRAM, 2013.

BRASIL. Secretaria de Educação Fundamental. Parâmetros curriculares nacionais: arte / Secretaria de Educação Fundamental. Brasília: MEC / SEF, 1998. 
BRASIL. Secretaria de Educação Fundamental. Parâmetros curriculares nacionais: terceiro e quarto ciclos do ensino fundamental: introdução aos parâmetros curriculares nacionais / Secretaria de Educação Fundamental. Brasília: MEC/SEF, 1998.

CABRAL SANTOS, Magaly de Oliveira. Lição das coisas (ou canteiro de obras) através de uma metodologia baseada na educação patrimonial. 1997. 137 p. Dissertação (Mestrado) Departamento de Educação, Pontifícia Universidade Católica, Rio de Janeiro.

COELHO, Marcelo A. Madonnaro: mediando saberes na escola a partir do Salão Preto e Branco. 31 de março de 2016. Disponível em: $<$ http://artesobrepavimento.blogspot.com.br/2016/03/madonnaro-mediando-saberes-na-escola.html $>$. Acesso em: $31 \mathrm{de}$ março de 2016.

DESVAlLÉES, André e MAIRESSE, François. Conceitos-chave de Museologia. São Paulo: Comitê Brasileiro do Conselho Internacional de Museus: Pinacoteca do Estado de São Paulo: Secretaria de Estado da Cultura, 2013.

FERRAZ, Maria Heloísa Corrêa de Toledo. A educação escolar em Arte tem uma história. \& REZENDE E FUSARI, Maria F. de. Metodologia do ensino de arte. São Paulo: Cortez, 1999. 2. ed. (Coleção magistério. $2^{\circ}$ grau. Série formação do professor).

FRANZ, Teresinha Sueli. Educação para a compreensão das Artes. In: Educação para a compreensão da arte. Florianópolis: Insular, 2001.

FREIRE, Paulo. Pedagogia da Autonomia - Saberes necessários à prática educativa. São Paulo: Paz e Terra, 1996. Coleção Leitura. 25ª Ed.

GASPAR, Alberto. Museus de Ciências - Breve relato histórico. In: . Museus e Centros de Ciências - Conceituação e proposta de um referencial teórico. Universidade de São Paulo; Faculdade de Educação. São Paulo, 1993. (Tese Doutorado)

GIRARDI, Mariana. A visita ao museu: perspectivas para a formação cultural de alunos do ensino fundamental. Disponível em: $<$ http://www.educasul.com.br/2010/Anais/trabalhos_educasul_curriculo_e_culturaescolar2/M ariana\%20Girardi.pdf $>$. Acesso em: 15 de abril de 2015. 15 p.

GOMES, Cristiana. Revolução Francesa. Disponível em: $<$ http://www.infoescola.com/historia/revolucao-francesa/>. Acesso em: 23 de abril de 2016.

JACOBUCCI, Daniela Franco Carvalho. Contribuições dos espaços não-formais de educação para a formação da cultura científica. Em extensão, Uberlândia (MG), v. 7, 2008. pp. 55-66.

KOPTCKE. L. S. Bárbaros, escravos e civilizados: o público dos museus no Brasil. IN: CHAGAS, M. (org.) Revista do Patrimônio Histórico e Artístico no Brasil - Museus, Rio de Janeiro: Iphan, n. 31, p. 184-205, 2005.

LEGISLAÇÃO SOBRE MUSEUS (Recurso eletrônico). $2^{\mathrm{a}}$ ed. Brasília: Câmara dos Deputados, Edições Câmara, 2013. 
LOPES, Maria Margaret. A favor da desescolarização dos museus. Educação \& Sociedade, $\mathrm{n}^{\circ} \quad 40, \quad$ dezembro, $1991 . \quad$ Disponível em: $<$ http://www.sisemsp.org.br/blog/wpcontent/uploads/2016/04/Afavordadesescolariza\%C3\%A 7\%C3\%A3o-dos-museus.pdf $>$. Acesso em: 21 de maio de 2016.

LUZ, Angela Ancora da. A XXXVIII Exposição Geral de Belas Artes e sua significação para a construção da modernidade no Brasil - o Salão de 31. In: Oitocentos - Arte Brasileira do Império à República - Tomo 2. Org. Arthur Valle; Camila Dazzi. Rio: EDURUFRRJ/DezenoveVinte, 2010. 1 Vol.

MORA, Paolo e Laura e PHILIPPOT, Paul. La conservazione delle pitture murali. Trad.: Bresciani S.r.1. 2a ed. Bologna: Editrice Compositori , 2001.

NAALIN, Felice. L'arte dei madonnari. Le tecniche. Del segno e del colore. Giunti Demetra, 2000.

RODINÒ, Simonetta Prosperi Valenti. Forme, Funcioni, Tipologie. In: SCIOLLA, Gianni Carlo (org.). Il disegno. Forme, tecniche, significati. Cinisello Balsamo (MI): Silvana Editoriale, 1991.

SANTOS, Maria Célia Teixeira Moura. Museu e Educação: Conceitos e Métodos. In: SANTOS, M. C. M. Encontros Museológicos. Rio de Janeiro: MinC/Iphan/DEMU, 2008. SCHULTZ, Valdemar. Leituras e releituras em aulas de artes visuais: práticas escolares e processos de criação. Disponível em:

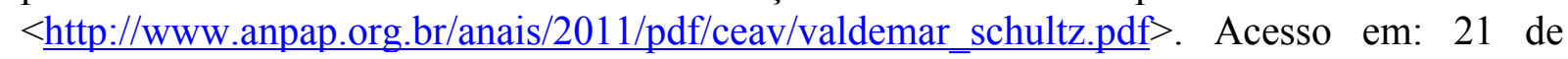
maio de 2016. pp. 1206-1219. 